\title{
Editorial Comment: Effect of pelvimetric diameters on success of surgery in patients submitted to robot-assisted perineal radical prostatectomy
}

\author{
Gilberto J. Rodrigues ${ }^{1}$, Rafael F. Coelho ${ }^{1}$ \\ ${ }^{1}$ Instituto do Câncer do Estado de São Paulo, Faculdade de Medicina da Universidade de São Paulo - USP, \\ São Paulo, SP, Brasil
}

\section{COMMENT}

The outcomes of Radical prostatectomy (RP), regardless of the surgical approach, play an important role on patients' quality of life, mainly due its impact on urinary and sexual function. These outcomes are dependent on multiple factors including patient's anatomy, age, comorbidities, tumor staging, surgeon's experience, nerve sparing approach among others (1-5). Several statistical models have been published trying to predict functional and oncologic outcomes of RP based on patients' factors and perioperative parameters; these models seek to optimize preoperative counseling and patient selection for RP. However, the outcomes of RP are widely variable and conflicting results were reported with regards the importance of each factor as an independent predictor of surgical outcomes (6-11). The truth is that perioperative, functional and oncological results of RP are far more difficult to estimate, and even unknown factors may play an important role on final outcomes. Thus, in daily clinical practice, those prediction models must be cautiously interpreted and shouldn't be used as a unique tool in patients counseling or to select a specific surgical approach.

Perineal prostatectomy (RPP) was the first and oldest surgical technique described for prostate cancer treatment, progressively replaced by retropubic prostatectomy (RRP) after the introduction and standardization of the nerve-sparing technique by Walsh $(12,13)$. As technology and surgical techniques evolved, minimally invasive surgery emerged with laparoscopic (LRP) and robotic-assisted prostatectomy (RARP) presenting shorter length of stay, minimal blood loss and potentially better functional outcomes $(14,15)$. Recently, RRP was adapted to robotic-assisted platform (P-RARP) and it has been described as an option in patients with previous multiple abdominal surgeries, who presents abdominal wall defect with a mesh, obese or transplanted kidney patients, for example $(16,17)$. However, the real benefits of this approach in terms of surgical outcomes are yet to be proven. Despite the quite interesting findings described by Yenice at al. (18) in the current study, correlating pelvimetric measurements and operative time (but not with positive surgical margins), this findings happens to be just one more of those inconsistent predictive models with controversial results compared to other series $(19,20)$ and must have minimal impact on the final decision.

\section{CONFLICT OF INTEREST}

None declared. 


\section{REFERENCES}

1. Chen J, Chu T, Ghodoussipour S, Bowman S, Patel H, King K, et al. Effect of surgeon experience and bony pelvic dimensions on surgical performance and patient outcomes in robot-assisted radical prostatectomy. BJU Int. 2019;124:828-35.

2. Ko WJ, Truesdale MD, Hruby GW, Landman J, Badani KK. Impacting factors for recovery of erectile function within 1 year following robotic-assisted laparoscopic radical prostatectomy. J Sex Med. 2011;8:1805-12.

3. Hung AJ, Chen J, Jarc A, Hatcher D, Djaladat H, Gill IS. Development and Validation of Objective Performance Metrics for Robot-Assisted Radical Prostatectomy: A Pilot Study. J Urol. 2018;199:296-304.

4. Antonelli A, Palumbo C, Noale M, Porreca A, Maggi S, Simeone $C$, et al. Impact of Surgical Approach on PatientReported Outcomes after Radical Prostatectomy: A Propensity Score-Weighted Analysis from a Multicenter, Prospective, Observational Study (The Pros-IT CNR Study). Urol Int. 2019;103:8-18.

5. Lardas M, Liew M, van den Bergh RC, De Santis M, Bellmunt J, Van den Broeck T, et al. Quality of Life Outcomes after Primary Treatment for Clinically Localised Prostate Cancer: A Systematic Review. Eur Urol. 2017;72:869-85.

6. Favorito LA. Age and Body Mass Index: the most important factors of urinary and erectile function recovery after robotic assisted radical prostatectomy. Int Braz J Urol. 2019;45:653-4.

7. Kanehira M, Takata R, Ishii S, Ito A, Ikarashi D, Matsuura T, et al. Predictive factors for short-term biochemical recurrence-free survival after robot-assisted laparoscopic radical prostatectomy in high-risk prostate cancer patients. Int $\mathrm{J}$ Clin Oncol. 2019;24:1099-104.

8. Moureaux C, Boucaud-Maitre D, Brureau L, Gourtaud G, Senechal C, Roux V, et al. Pelvimetrics measures as predictives factors of positives surgical margins after robot-assisted laparoscopic prostatectomy. Prog Urol. 2018;28:906-14.

9. Matikainen MP, von Bodman CJ, Secin FP, Yunis LH, Vora K, Guillonneau B, et al. The depth of the prostatic apex is an independent predictor of positive apical margins at radical prostatectomy. BJU Int. 2010;106:622-6.

10. Coelho RF, Cordeiro MD, Padovani GP, Localli R, Fonseca L, Pontes J Júnior, et al. Predictive factors for prolonged hospital stay after retropubic radical prostatectomy in a high-volume teaching center. Int Braz J Urol. 2018;44:1089-105.

11. Ko YH, Coelho RF, Chauhan S, Sivaraman A, Schatloff 0 , Cheon $J$, et al. Factors affecting return of continence 3 months after robot-assisted radical prostatectomy: analysis from a large, prospective data by a single surgeon. J Urol. 2012;187:190-4.

12. Young $\mathrm{HH}$. The early diagnosis and radical cure of carcinoma of the prostate. Being a study of 40 cases and presentation of a radical operation which was carried out in four cases. 1905. J Urol. 2002;167(2 Pt 2):939-46; discussion 947.
13. Walsh PC, Lepor H, Eggleston JC. Radical prostatectomy with preservation of sexual function: anatomical and pathological considerations. Prostate. 1983;4:473-85.

14. Ilic D, Evans SM, Allan CA, Jung JH, Murphy D, Frydenberg M. Laparoscopic and robotic-assisted versus open radical prostatectomy for the treatment of localised prostate cancer. Cochrane Database Syst Rev. 2017;9:CD009625.

15. Yaxley JW, Coughlin GD, Chambers SK, Occhipinti S, Samaratunga H, Zajdlewicz L, et al. Robot-assisted laparoscopic prostatectomy versus open radical retropubic prostatectomy: early outcomes from a randomised controlled phase 3 study. Lancet. 2016;388:1057-66.

16. Laydner H, Akça O, Autorino R, Eyraud R, Zargar H, Brandao LF, et al. Perineal robot-assisted laparoscopic radical prostatectomy: feasibility study in the cadaver model. J Endourol. 2014;28:1479-86.

17. Ekși M, Çolakoğlu Y, Tuğcu V, Sahin S, Simsek A, Evren İ, et al. Robot Assisted Radical Perineal Prostatectomy; Review of 95 Cases. BJU Int. 2020;27. [Epub ahead of print]

18. Yenice MG, Yigitbasi I, Turkay R, Sahin S, Tugcu V. Effect of pelvimetric diameters on success of surgery in patients submitted to robot-assisted perineal radical prostatectomy. Int Braz J Urol. 2020;46: 425-33.

19. Moureaux C, Boucaud-Maitre D, Brureau L, Gourtaud G, Senechal C, Roux V, et al. Pelvimetrics measures as predictives factors of positives surgical margins after robot-assisted laparoscopic prostatectomy. Prog Urol. 2018;28:906-14.

20. Matikainen MP, von Bodman CJ, Secin FP, Yunis LH, Vora $\mathrm{K}$, Guillonneau B, et al. The depth of the prostatic apex is an independent predictor of positive apical margins at radical prostatectomy. BJU Int. 2010;106:622-6.

ARTICLE INFO

Rafael F. Coelho

https://orcid.org/0000-0003-3835-0789

Int Braz J Urol. 2020; 46: 434-5

Submitted for publication: January 25, 2020

Accepted after revision: February 10, 2020

Rafael F. Coelho, MD

Instituto do Câncer do Estado de São Paulo, Faculdade de Medicina da Universidade de São Paulo - USP Av. Dr. Arnaldo, 455 - Cerqueira César São Paulo, SP, 01246-903, Brasil E-mail: coelhouro@yahoo.com.br 